\title{
Thermodynamic Steady-State Analysis and Comparison of Compressed Air Energy Storage (CAES) Concepts
}

\author{
Friederike Kaiser*(1), Roman Weber ${ }^{(2)}$, Uwe Krüger $^{(3)}$ \\ (1) Forschungszentrum Energiespeichertechnologien, TU Clausthal, D-38678 Clausthal-Zellerfeld, Germany \\ (2) Institut für Energieverfahrenstechnik und Brennstofftechnik, TU Clausthal, D-38678 Clausthal-Zellerfeld \\ (3) Power Plants Group Wilhelmshaven, Uniper Kraftwerke GmbH, E.ON-Platz 1, 40479 Duesseldorf, Germany \\ E-Mail: friederike.kaiser@tu-clausthal.de
}

Received 19 March 2018, Accepted 04 June 2018

\begin{abstract}
Different compressed air energy storage (CAES) schemes - as options for large-scale energy storage - are compared through a thermodynamic steady-state analysis by determining the state variables based on irreversibility and real gas behaviour. Characteristic values (such as technical work, power and efficiency) of Huntorf and McIntosh plants as well as several advanced concepts under development (adiabatic, isobaric and quasi-isothermal CAES) are considered. The calculation methods are validated with a newly collected comprehensive set of measured operational data of the reference plant Huntorf making this review unique and novel. It is found that in the existing CAES plants the largest energy loss occurs during compression by inter-cooling the compressed air (around $95 \%$ ). Thus, to enhance energy storage efficiency adiabatic and isothermal concepts are encouraged since they can lead to significantly higher values. The ambiguous energy storage efficiency of CAES is discussed in detail. The turbine conversion coefficient which in conventional gas turbines usually does not exceed $45 \%$ or $60 \%$ in combined cycle power plants respectively can reach in CAES turbines more than $80 \%$.
\end{abstract}

Keywords: Compressed air energy storage; thermodynamic power cycle; storage efficiency; comparison adiabatic CAES; steady state.

\section{Basic Principle of Compressed Air Energy Storage}

The essential elements of CAES are: an electrical motor-generator $(\mathrm{M} / \mathrm{G})$, an air compressor (C), a compressed air storage (S), a burner (B) and a gas turbine (T), see Figure 1.
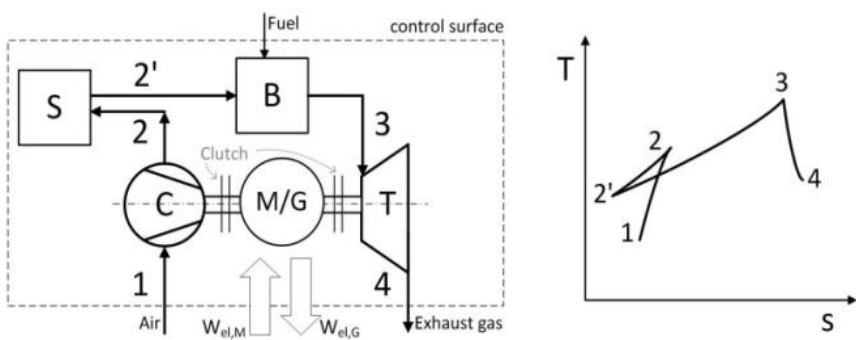

Figure 1. CAES open circuit and T-s diagram (with $M / G$ electrical motor/generator, $C$ - compressor, $S$ - compressed air storage, B- burner, $T$ - turbine (adapted from [1,2]).

When a surplus of electricity occurs, the motor (M) drives the air compressor $(\mathrm{C})$ and the compressed air is then stored in the storage place $(\mathrm{S})$. The electrical work needed to drive the compression is marked in Figure 1 as $\mathrm{W}_{\mathrm{el}, \mathrm{M}}$. On repowering, a fuel is burned in the burner (B) and the highpressure combustion products expand in the turbine (T) which drives the electricity generator $(G)$. The work produced in the generator is marked in Figure 1 as $W_{\text {el,G. }}$. The two clutches allow for coupling the motor-generator with either compressor or gas turbine. In the T-s diagram shown in Figure 1, path 1-2 represents air compression, path 2-2' indicates air storage, 2'-3 shows combustion whilst 3-4 represents expansion.

From the thermodynamic point of view the CAES is a non-cyclic open-circuit process with air, fuel and exhaust gas stream, as well as electrical work, crossing the control surface. More precisely, Figure 1 shows two distinct processes: The first one, marked by path $1-2-2$, is a conversion of the electrical energy (work $-W_{e l, M}$ ) into compressed air energy and its storage (in what follows also referred to as "charge" mode) whilst the second process, marked by 2'-3-4 path, is a conversion of both the stored compressed air energy and the fuel chemical energy into electrical energy $\left(W_{e l, G}\right)$ ("discharge" mode). Such a distinction is useful since the processes 1-2-2' and 2'-3-4 do not proceed simultaneously.

The CAES shown in Figure 1 is somewhat similar to an open-circuit gas turbine plant whose simplified circuit is shown in Figure 2 together with an associated T-s diagram; path 1-2 shows the compression, path 2-3 combustion while path 3-4 indicates expansion. In a gas turbine open-circuit, air-stream and fuel-stream enter the control surface while combustion products and electrical work $\left(\mathrm{W}_{\mathrm{el}, \mathrm{G}}\right)$ leave the control surface. The essential difference to CAES is that the compression, combustion and expansion proceed simultaneously. Thus, the electrical work leaving the control surface of an open-circuit gas turbine power plant is the difference between expansion and compression work. For example, for a typical gas turbine plant producing 100 MW power, the turbine would generate around $250 \mathrm{MW}$ of which around $150 \mathrm{MW}$ would be needed to run the compressor. 

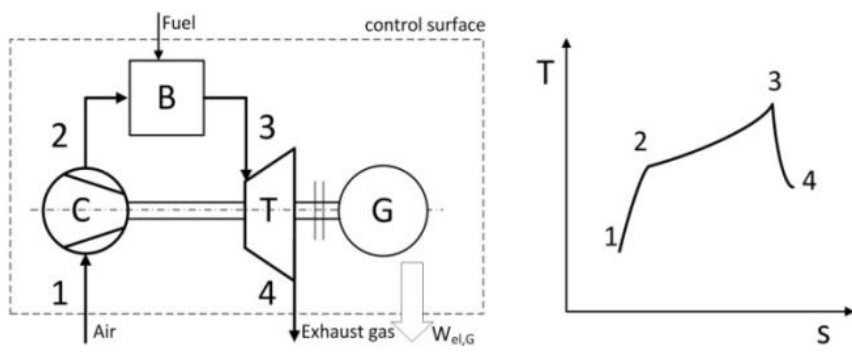

Figure 2. Open-circuit gas turbine and T-S diagram (adapted from [3,4]).

Hence, decoupled operation of compressor and turbine is an important feature of CAES making a large power span available (in the example -150 to $+250 \mathrm{MW}$ power, which quadruples the power range of a conventional $100 \mathrm{MW}$ gas turbine, from a grid point of view).

The CAES process, such as the one shown in Figure 1, is furthermore inherently time-dependent since during charging the pressure, temperature, and to a certain degree even the air flow rate, vary with time. During repowering variations in the pressure, temperature, airflow rate, fuel gas flow rate do occur. Thus, strictly speaking, considerations and comparisons of different CAES concepts should include time-dependent simulations in which the thermodynamics of charging and discharging the storage should be properly handled. Such an analysis is however beyond the scope of this analysis and here the assessment of the CAES systems is based exclusively on an analysis of engineering circuits at steady state.

In discussing performance criteria, we are using the concept of work whose inexact differential is defined as

$\delta w_{t}=v d p$

and

$w_{t}=\int_{\text {initial }}^{\text {final }} v d p$

In German literature on technical thermodynamics [4-6] the above expression represents so called specific "technical" work (in $\mathrm{J} / \mathrm{kg}$ ) as opposed to volume work, hence the subscript " $t$ ". Upon compression, the technical work is positive whilst it is negative upon expansion. The first law of thermodynamics is used here in the following formulation applicable to irreversible processes:

$d h=\delta q+\delta w_{t}+\delta w_{\text {friction }}=T d s+\delta w_{t}$

where $d h$ and $d s$ are the exact differentials of enthalpy and entropy, respectively; $\delta q$ and $\delta w_{\text {friction }}$ are the inexact differentials of heat provided to the system and the inexact differential of friction work, respectively. If, in the thermodynamic analysis that follows, the processes are treated as reversible the friction work is omitted: $\delta w_{\text {friction }}=$ 0 .

The thermodynamic analysis of the various CAES concepts in this paper is carried out using the Engineering Equation Solver (EES). Gases are treated as real. For air, the non-dimensional Helmholtz equation of state [7] is used and enthalpy and entropy are calculated using differentiation with respect to density and temperature.

\section{Previous Publications and Novelty of This Work}

A comprehensive literature review for the topic of this paper is presented in the corresponding working paper [8]. More general reviews are presented by Budt et al. [9] who give an overview of CAES history and recent developments. Their review [9] includes thermodynamic considerations on exergy, efficiencies and fluid properties. Huntorf and McIntosh plants are described using generally available (literature) process data and several advanced CAES systems are elaborated upon in more detail.

The number of publications on CAES is vast and ever growing. However, no detailed thermodynamic steady-state analyses has been carried out in which the gas is treated as real and calculation methods are validated based on a detailed set of measured operational data from one of the two existing commercial reference plants to further use these methods to consistently handle process irreversibilities for both the existing CAES plants and the forthcoming (conceptual) designs.

It is important to realize that the data earlier published from the Huntorf CAES plant [10-17] is incomplete, from the thermodynamic point of view, and does not allow, for example, for an accurate estimate of thermodynamic inner efficiencies of compression/expansion stages. We remedy this situation by presenting a comprehensive set of plant thermodynamic data (see Table A1) that allows for a (more) precise determination of the inner efficiencies of individual compression/expansion stages. The subsequent thermodynamic analysis leads to an objective assessment of various assumptions/models (ideal gas, real gas, reversibility against irreversibility) through the comparison with the new data. It is perhaps fair to say that Huntorf plant has become the reference plant for many other CAES concepts under development. It is therefore of paramount importance that the plant thermodynamics is correctly determined since it largely contributes to the development of calculation methods for CAES processes in general.

\section{Calculation Methods and Analysis Based on Operational Data of the Huntorf CAES Plant}

Figure 3 shows a process flow diagram of the Huntorf CAES plant with a subdivision into two operation modes 'Charge' and 'Discharge'.

- Charge For charging, a compression with several stages is used since the pressure ratio $\left(\mathrm{p}_{8} / \mathrm{p}_{1}\right)$ is high varying in the overall range of $20: 1$ to $68: 1$ corresponding to the minimum (20 bar) and maximum ( 68 bar) cavern pressures. The compression is divided into a low pressure and a high pressure unit. The low pressure compressor $\left(\mathrm{C}_{\mathrm{I}}\right)$ is a one stage axial compressor followed by a cooling stage. The high pressure compressor is a six stage centrifugal unit with cooling after every two stages [14]. Thus, each two high pressure compressor stages are treated as one unit, as indicated in Figure $3\left(\mathrm{C}_{\mathrm{II}}, \mathrm{C}_{\mathrm{III}}\right.$, and $\left.\mathrm{C}_{\mathrm{IV}}\right)$. Inter-cooling between the compressor stages reduces the work required for compression ( $\mathrm{IC}_{\mathrm{I}}$ to $\mathrm{IC}_{\mathrm{III}}$ in Figure 3). After the compression, a cooling is required $\left(\mathrm{IC}_{\mathrm{IV}}\right)$ to cool down the air to the permissible inlet temperature of the cavern (50

${ }^{\circ} \mathrm{C}$ ). During charging, the air mass flow rate is kept at $108 \mathrm{~kg} / \mathrm{s}$ [13-14]. 


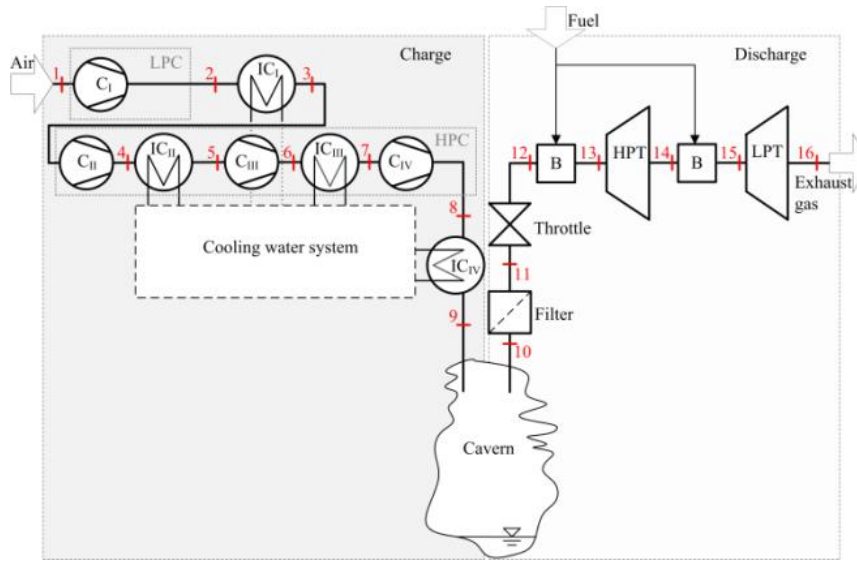

Figure 3. Process flow diagram of Huntorf CAES, subdivided into 'Charge' and 'Discharge' ( $C$ - compressor; IC - inter-cooler; $T$ - turbine; B - burner) (adapted from $[10,13])$.

- Cavern The compressed air is stored in two solution-mined salt caverns of around 140,000 and 170,000 $m^{3}$ volumes [13]. Typically both caverns are used simultaneously as if it were a single storage volume of $310,000 \mathrm{~m}^{3}$. The advantage of two separate caverns appears when one cavern is emptied to atmospheric pressure for repair or maintenance. The second cavern is then used to refill the first one to a minimum pressure (>20 bar), that is required to operate the compressor train [13]. Without this option an additional compressor would have to be used to refill the empty cavern.

- Discharge In discharging mode, the air mass flow rate amounts to $455 \mathrm{~kg} / \mathrm{s}$ in a full load operation. The air is filtered, then passes through a throttle, and is expanded in two turbines: a high pressure turbine (HPT) and a low pressure turbine (LPT), each with supplementary firing of natural gas. If the cavern pressure is in the 46 to $68 \mathrm{bar}$ range, the turbines are operated at full load.

\section{- Thermodynamic Data}

In Figure 3 and Table A1 (see Appendix) numbers $i=1$ to 16 indicate the thermodynamic states of the process. The design parameters $[10,13,14]$ are listed in Table A1 using bold face font. Table A1 contains also several sets of measured data (temperature, pressure, flow rates): four sets for charging (indicated in Table A1 by $t=1,2,3,4$ ) and three sets for discharging $(t=5,6,7)$.

\subsection{Inner Efficiency}

\section{- Charge}

The measured data are used to determine the inner (thermodynamic) efficiency of compression (often referred to as isentropic efficiency). Since temperatures and pressures have been measured at points 1 and 2 (see Table A1), the inner efficiency $\left(\eta_{\mathrm{s}}\right)$ is obtained upon solving the equations

$s\left(T_{1}, p_{1}\right)=s\left(T_{2 s}, p_{2}\right)$

and

$\eta_{S}(L P T)=\frac{h\left(T_{2 s}, p_{2}\right)-h\left(T_{1}, p_{1}\right)}{h\left(T_{2}, p_{2}\right)-h\left(T_{1}, p_{1}\right)}$ where $s(T, p)$ and $h(T, p)$ are appropriate functions for specific entropy and specific enthalpy of air treated as a real gas; $T_{2 S}$ represents the temperature of isentropic compression.

The arithmetic average of the four sets of measured data $(t=1,2,3,4)$ gives $\eta_{s}(L P C)=0.844$ which corresponds to $\mathrm{T}_{2}$ $=502 \mathrm{~K}$; typical values for $\eta_{s}$ lie within 0.70 to 0.88 range [3] or for the newest turbo compressors even within 0.86 to 0.90 range [4,5]. The inner efficiencies $\eta_{s}$ of the HPC stages are obtained in the same way and the results are given in Table 1.

To reduce the technical work needed for the overall compression, each compression stage is followed by an inter-cooler ( $\mathrm{IC}_{\mathrm{I}}$ to $\mathrm{IC}_{\mathrm{III}}$ in Figure 3) [10]. The compressed air is cooled down to $\mathrm{T}_{3}=308 \mathrm{~K}$ using water and the pressure stays nearly constant at 6 bar. Yet, a small pressure loss occurs and is estimated, using procedures applicable to tubular heat exchangers [18] to be 10 mbar.

The inter-staged pressures of $\mathrm{C}_{\mathrm{II}}, \mathrm{C}_{\mathrm{III}}$ and $\mathrm{C}_{\mathrm{IV}}$ vary with the cavern pressure since the overall compression ratio $\left(\mathrm{p}_{8} / \mathrm{p}_{2}\right)$ varies from 20:6 (empty caverns) to 68:6 (full caverns). It is assumed, that the inter-stage pressures of the HPC correspond to those pressures that lead to a minimum overall technical work. Thus, for a three-staged compression, from 6 bar to the maximum cavern pressure of $\mathrm{p}_{8}=68 \mathrm{bar}$, the compression ratio $\xi$ is:

$\zeta=\frac{p_{8}^{1 / 2}}{p_{3}}=2.246$

and the inter-staged pressures are then $\mathrm{p}_{4}=13.5$ bar and $p_{6}$ $=30.3 \mathrm{bar}$.

The temperature and pressure values at points 4 to 8 are calculated following the same procedure (see Eqs. (4),(5)). The pressure losses in the inter-coolers increase with the pressure levels, see Table $\mathrm{A} 2$. The after-cooler $\left(\mathrm{IC}_{\mathrm{IV}}\right.$ in Figure 3) makes sure that the temperature of the compressed air does not exceed the maximum allowable temperature of the cavern $(323 \mathrm{~K})$, thus the compressed air is cooled to $T_{9}=322 \mathrm{~K}$. A pressure loss of $800 \mathrm{mbar}$ is estimated.

Table 1: Inner efficiencies $\left(\eta_{s}\right)$ of the compressors $(C)$ and turbines $(T)$ calculated using measured Huntorf data.

\begin{tabular}{|c|c|c|}
\hline & Process unit & Inner efficiency $\eta_{s}$ \\
\hline \multirow[t]{4}{*}{ Charge } & $\mathrm{CI}_{\mathrm{I}}$ & 0.844 \\
\hline & $\mathrm{C}_{\text {II }}$ & 0.726 \\
\hline & $\mathrm{C}_{\text {IIII }}$ & 0.764 \\
\hline & $\mathrm{C}_{\mathrm{IV}}$ & 0.653 \\
\hline \multirow[t]{2}{*}{ Discharge } & HPT & 0.894 \\
\hline & LPT & 0.894 \\
\hline
\end{tabular}

\section{- Discharge}

After leaving the cavern the air is filtered. Due to a high air velocity (up to $30 \mathrm{~m} / \mathrm{s}$ [15]) at the cavern exit and due to the filters, a pressure loss of around 4 bar occurs during full load operation so the maximum pressure at the filter outlet is $p_{11}=64$ bar. Further reduction to $p_{12}=42$ bar pressure is then caused by a throttle so as to keep, under consideration of a pressure loss inside the combustion chambers of approximately $0.7 \mathrm{bar}$, a constant pressure of $p_{13}=41.3$ bar at the turbine inlet at full load operation. The throttling is an isenthalpic pressure drop that comes along with a temperature change (Joule-Thomson-Effect). To 
calculate the outlet temperature $\mathrm{T}_{12}$ of the throttle, the equation $\mathrm{h}\left(\mathrm{T}_{11}, \mathrm{p}_{11}\right)=\mathrm{h}\left(\mathrm{T}_{12}, \mathrm{p}_{12}\right)$ is solved with an appropriate function for the enthalpy of air treated as a real gas.

If the cavern pressure drops below 46 bar, no more throttling is used and the turbine starts to operate in a part load.

In the burner, natural gas is injected into the throttled air to increase the temperature to the design value of $T_{13}=$ $763 \mathrm{~K}$ so as to avoid icing. The outlet pressure of the HPT $\left(\mathrm{p}_{14}\right)$ corresponds to the inlet pressure of the LPT $\left(\mathrm{p}_{15}\right)$ plus the pressure loss inside the second combustion chamber that is set equal to the pressure loss of the first combustion chamber $(0.7$ bar $)$.

Since the outlet temperature of the turbine $\left(\mathrm{T}_{14}\right)$ has been measured (see Table A1) the inner efficiency of the HP expansion can be calculated as

$$
\eta_{S}(H P T)=\frac{h\left(T_{13}, p_{13}\right)-h\left(T_{14}, p_{14}\right)}{h\left(T_{13}, p_{13}\right)-h\left(T_{14 s}, p_{14}\right)}
$$

where $T_{14 \mathrm{~s}}$ is the outlet temperature of the turbine under reversibility assumption which is obtained upon solving $\mathrm{s}_{13}\left(p_{13}, T_{13}\right)=s_{14}\left(p_{14}, T_{14 \mathrm{~s}}\right)$ equation. The value of $\eta_{\mathrm{s}}(\mathrm{HPT})$ of 0.894 listed in Table 1 is an arithmetic average of the HPT expansion efficiencies derived using the three sets of the measured data $(t=5,6,7$ in Table A1). It has to be noted that the measured data represents a part load operation, thus the resulting inner efficiency might be slightly underestimated for a full load operation. Similar calculations for the LPT provide also an inner efficiency of 0.894, see Table 1.

\subsection{State Variables}

With the above described calculations, the thermodynamic state variables at points 1 to 16 are described as a function of temperature and pressure, e.g. specific entropy $s_{\mathrm{i}}=s\left(p_{\mathrm{i}}, T_{\mathrm{i}}\right)$ and enthalpy $h_{\mathrm{i}}=h\left(p_{\mathrm{i}}, T_{\mathrm{i}}\right)$. The reference state for specific entropy is based on the third law of thermodynamics ( $s=0 \mathrm{~kJ} / \mathrm{kg}$ at $T=0 \mathrm{~K}$ and $p=1.01325 \mathrm{bar}$ ) while the reference state for enthalpy is based on the enthalpy of formation relative to the elements at $25^{\circ} \mathrm{C}(h=0$ $\mathrm{kJ} / \mathrm{kg}$ at $\mathrm{T}=298.15 \mathrm{~K}$ and $\mathrm{p}=1.01325 \mathrm{bar}$ ).

Table A2 lists the calculated thermodynamic variables for the Huntorf process, whilst Figure 4 shows the Huntorf open cycle circuit as h-s-diagram. Table A2 see Appendix.

\subsection{Technical Work and Heat}

Based on the above presented thermodynamic state variables, the enthalpy difference of each process stage can be determined. For the compression (C) and expansion (T) the enthalpy difference corresponds to the specific technical work $\left(w_{t}\right)$. For the inter- and after-cooler, it corresponds to the transferred heat $\mathrm{q}_{\text {loss }}$ whilst for the burner to $q_{\text {fuel. }}$ Thus, for 68 bar cavern pressure the technical work of the low pressure compressor (LPC) amounts to $\left(h_{2}-h_{1}\right)=223 \mathrm{~kJ} / \mathrm{kg}$; for the high pressure compressor (HPC) a figure of $\left(h_{4}-h_{3}+h_{6}-h_{5}+h_{8}-h_{7}\right)=342 \mathrm{~kJ} / \mathrm{kg}$ is applicable. The heat removed after the LPC amounts to $\left(h_{3}-h_{2}\right)=199 \mathrm{~kJ} / \mathrm{kg}$ while the heat removed after the HPC is $\left(h_{5}-h_{4}+h_{7}-h_{6}+h_{9}-h_{8}\right)=$ $-339 \mathrm{~kJ} / \mathrm{kg}$.

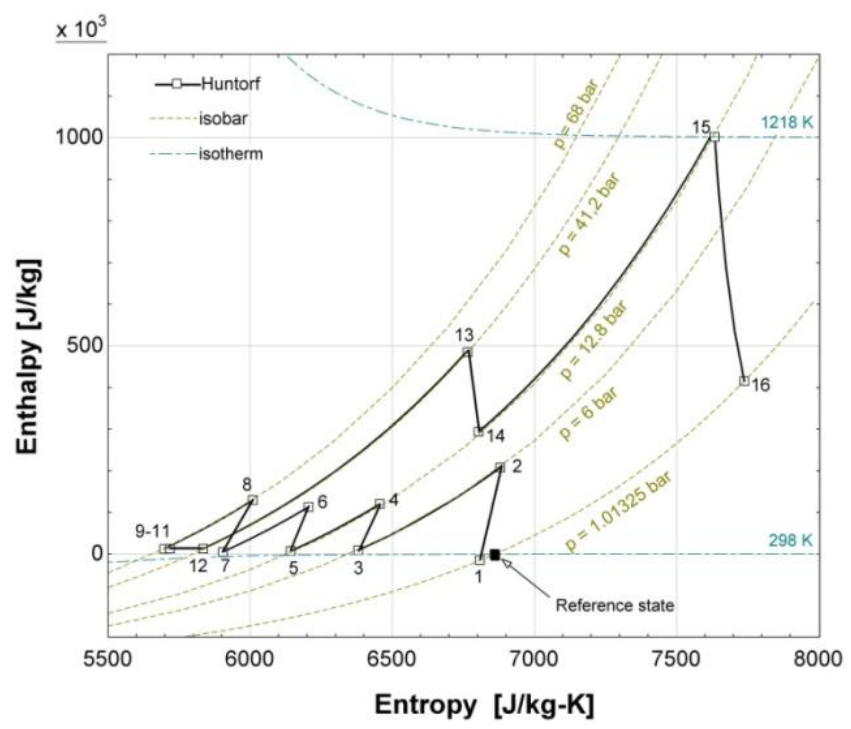

Figure 4: h-s diagram of Huntorf CAES.

Both the work and heat figures are summarized in Table 2 and compared with values (given in brackets) corresponding to reversible processes $\left(\eta_{\mathrm{s}}=1\right)$. Since the technical work for the compression increases with the cavern pressure, the lower (46 bar) and upper limit (68 bar) of the cavern pressure at full load operation are used as a parameter in Table 2.

The comparison shows that the technical work $\left(\mathrm{w}_{\mathrm{t}}\right)$ of the polytropic and reversible processes differ significantly. Furthermore, it can be seen that a considerable part of the technical work to compress the air is dissipated in the interand after-cooling, hence lost energy ( $\left.\mathrm{q}_{\text {loss }}\right)$. The effect of throttling is not negligible as shows the comparison of the technical work for the 46 bar and 68 bar cavern pressure.

During discharge, in a full load operation (cavern pressure in the 46 to 68 bar range), the pressure has no effect on the technical work of the turbines since the turbine inlet pressure remains constant at 41.3 bar due to the throttling.

Table 2. Specific technical work $\left(w_{t}\right)$ and heat exchanged (q) for the Huntorf plant for the minimum (46 bar) and maximum (68 bar) cavern pressure; values in brackets correspond to the reversible processes $\left(\eta_{s}=1\right)$.

Specific technical work $\left(w_{t}\right)$ and heat exchanged $(q)$ for polytropic (and reversible) process in [kJ/kg]

\begin{tabular}{llll}
\hline Parameter & Cavern pressure & 46 bar & 70 bar \\
Charge & $\mathrm{w}_{\mathrm{t}, \mathrm{LPC}}$ & $223(188)$ & $223(188)$ \\
& $\mathrm{w}_{\mathrm{t}, \mathrm{HPC}}$ & $281(199)$ & $342(243)$ \\
& $\mathrm{w}_{\mathrm{t}, \mathrm{C}}($ total $)$ & $504(387)$ & $565(431)$ \\
& $\mathrm{q}_{\text {loss }}$ & $-473(-357)$ & $-583(-404)$ \\
\hline Discharge & $\mathrm{w}_{\mathrm{t}, \mathrm{HPT}}$ & $-191(-222)$ \\
& $\mathrm{w}_{\mathrm{t}, \mathrm{LPT}}$ & $-587(-657)$ \\
& $\mathrm{w}_{\mathrm{t}, \mathrm{T}}($ total $)$ & $-778(-879)$ \\
& $\mathrm{q}_{\mathrm{fuel}}$ & $1180(1255)$ \\
\hline
\end{tabular}

In the HP burner, natural gas is burned to heat up the compressed air to a temperature of $T_{13}=763 \mathrm{~K}$. Thus, the heat added amounts to $\mathrm{h}_{13}-\mathrm{h}_{12}=q_{\text {fuel }}(\mathrm{HPT})=472 \mathrm{~kJ} / \mathrm{kg}_{\text {air }}$ and a work of $\mathrm{h}_{14}-\mathrm{h}_{13}=-191 \mathrm{~kJ} / \mathrm{kg}$ is obtained from this turbine unit. For the LP expansion $\mathrm{h}_{15}-\mathrm{h}_{14}=\mathrm{q}_{\text {fuel }}(\mathrm{LPT})=709 \mathrm{~kJ} / \mathrm{kg}_{\text {air }}$ is supplied and a technical work of $-587 \mathrm{~kJ} / \mathrm{kg}$ is obtained. 
The exhaust gas has a temperature of approximately $T_{16}=700 \mathrm{~K}$, hence the exhaust gas enthalpy is $h_{16}=415$ $\mathrm{kJ} / \mathrm{kg}$

\subsection{Mechanical Efficiency}

During charging the cavern with $108 \mathrm{~kg} / \mathrm{s}$ air flow rate at 68 bar cavern pressure, it has been measured that the LPC and HPC units take from the electrical grid a power of $27 \mathrm{MW}$ and $41 \mathrm{MW}$, respectively. On repowering, at $455 \mathrm{~kg} / \mathrm{s}$ air flow rate, the turbines (HPT+LPT) deliver $321 \mathrm{MW}$ to the grid. Thus, the data allows for estimating the mechanical efficiency $\left(\eta_{\text {mech }}\right)$ for compression:

$\eta_{\text {mech,c }}=\frac{p_{\text {thermod }}}{p_{\text {el }}}$

and for expansion:

$\eta_{\text {mech, } \mathrm{T}}=\frac{p_{\mathrm{el}}}{p_{\text {thermod }}}$

where $P_{\text {el. }}$ stands for the electrical power taken from or delivered to the grid while $P_{\text {thermod. }}$ is the thermodynamic power of the compression/expansion part of the cycle that is simply the product of the air mass flow rate and the specific technical work listed in Table 2. Such calculated mechanical efficiency $\left(\eta_{\text {mech }}\right)$ includes all mechanical losses of the compressor/turbine train, the shaft, the clutches and the motor/generator unit; the values are presented in Table 3. The mechanical efficiency of the whole turbine train is estimated to be 0.91 (see Table 3). Assuming that the overall mechanical efficiency of the turbine train applies to both turbine units, a $79 \mathrm{MW}$ power is delivered to the grid by the HPT, while $243 \mathrm{MW}$ by the LPT (322 MW in total).

Table 3. Electrical, thermodynamic power and mechanical efficiencies for Huntorf CAES (68 bar cavern pressure).

\begin{tabular}{|c|c|c|c|}
\hline \multirow[t]{3}{*}{ Process unit } & Electrical & Termodynamic & Mechanical \\
\hline & Power & Power & Efficiency \\
\hline & $P_{\text {el. }}$ in $\mathrm{MW}$ & $P_{\text {thermod. in } \mathrm{MW}}$ & $\eta_{\text {mech }}$ \\
\hline LPC & 27 & 24 & 0.89 \\
\hline HPC & 41 & 37 & 0.90 \\
\hline Compression & 68 & 61 & 0.90 \\
\hline HPT & n.a. & 87 & n.a. \\
\hline LPT & n.a. & 267 & n.a \\
\hline Expansion & 321 & 355 & 0.91 \\
\hline
\end{tabular}

Similar considerations apply to the enthalpy added to the fluid stream during combustion $\left(\dot{Q}_{\text {thermod. }}\right)$ in comparison with the fuel enthalpy $\left(\dot{Q}_{\text {fuel }}\right)$. Heat losses from the burner to the surroundings can be taken into account by the burner efficiency:

$\eta$ (burner $)=\frac{Q_{\text {thermod }}}{Q_{\text {fuel }}}$

It is assumed that heat losses in the burner are negligible and the burner efficiency is one.

The Huntorf CAES plant uses natural gas of type "L" according to the specification of DVGW [19]. For further estimates the Lower Calorific Value (LCV) of 8.861 $\mathrm{kWh} / \mathrm{m}^{3}(41 \mathrm{MJ} / \mathrm{kg})$ is used.

\subsection{Cavern Size and Operation Duration}

The size of the air reservoir $\left(V=310,000 \mathrm{~m}^{3}\right)$, as well as the minimum and maximum cavern pressures (46 to 68 bar), determine, together with the air flow rate, the full load operation duration. The two theoretically limiting cases are: a cavern with perfectly heat conducting rock thus having a constant temperature (isothermal cavern) and a perfectly isolated, adiabatic cavern. The pressure variation over time in an isotherm cavern for charging (air mass flow rate of $108 \mathrm{~kg} / \mathrm{s}$ ), which is followed by discharging at full load operation $(-455 \mathrm{~kg} / \mathrm{s}$ ) (cavern pressure variations from 46 bar to 68 bar), is depicted in Figure 5 with charging duration $\left(t_{c}\right)$ of 19.8 and discharging $\left(t_{d}\right)$ of 4.7 hours. The other limiting case is an adiabatic cavern that would have a charging period of $t_{c}=12.84$ and discharging $t_{d}=3.05$ hours, respectively.

In the literature on Huntorf CAES the discharging period with a mass flow rate of $\dot{m}_{d}=417 \mathrm{~kg} / \mathrm{s}$ is reported to be between 2 [10,12], 3 [13] and 4.5 hours [16]. Charging, at $\dot{m}_{c}=108 \mathrm{~kg} / \mathrm{s}$ flow rate, lasts between $8[10,12]$ and 19 hours [13]. Calculations on dynamic thermodynamic behaviour of Huntorf's cavern have been carried out by Raju and Khaitan [20,21,22], Kushnir et al. [23,24] and Xia et al. [25].

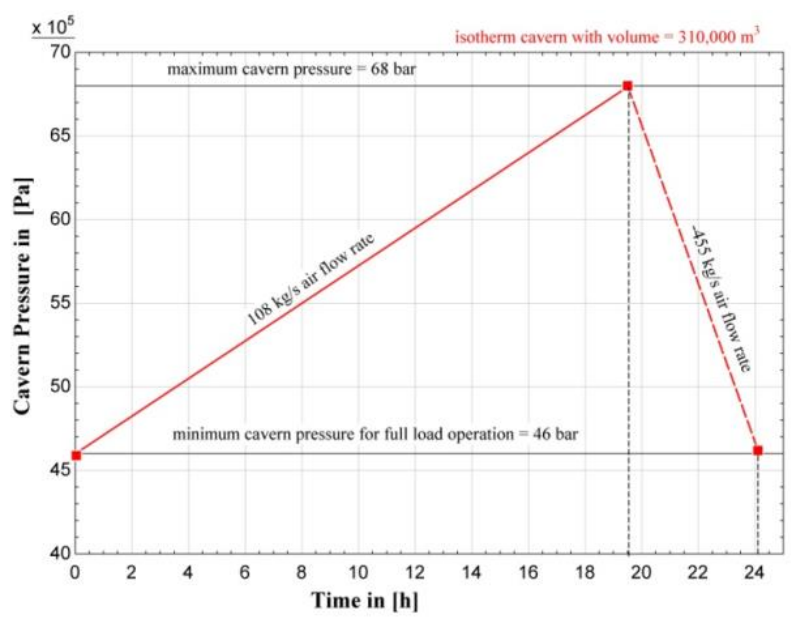

Figure 5. Cavern pressure of Huntorf CAES over one charging and discharging period for an isotherm cavern.

The charging- to discharging-time ratio is equal to the mass flow rate ratio of $455 \mathrm{~kg} / \mathrm{s}: 108 \mathrm{~kg} / \mathrm{s}=4.21$; the figure is valid for isothermal operation (19.8 h:4.7 h) as well as for adiabatic operation $(12.84 \mathrm{~h}: 3.05 \mathrm{~h})$ or any other constellation that assumes that no mass losses occur (tight storage place).

The rates of cavern pressure changes during charging and discharging (slopes in Figure 5) are important geomechanical parameters, which should not exceed allowable values in order not to compromise the mechanical integrity of the caverns. The allowable absolute values for Huntorf's caverns are according to different literature sources either $10 \mathrm{bar} / \mathrm{h}[10,15]$ or $15 \mathrm{bar} / \mathrm{h}$ [13]. The slopes, as depicted in Figure 5, are $1.2 \mathrm{bar} / \mathrm{h}$ and $-4.9 \mathrm{bar} / \mathrm{h}$ for charging and discharging, respectively (valid for an isothermal cavern).

\subsection{Energy Storage Efficiencies}

Generally, efficiency of a process or a machine is defined as the ratio of useful output (product) to the efforts put into producing the output. For thermodynamic 
processes it is then the ratio of useful (technical) work produced to the energy input:

$$
\eta=\frac{\text { useful work produced }}{\text { energy input }}
$$

Application of this definition to heat engines is rather straight forward since both the useful work produced and the energy input are easy to define (see Figure 6(a)). Similarly, when electrical energy is stored in batteries, in a Pumped Hydro Energy Storage system or in an Adiabatic CAES system, there are no ambiguities in defining the terms appearing in the above definition (see Figure 6(b)). Problems arise when the above definition is applied to a CAES system where the goal is to store electrical energy and, in order to carry out such storage, fuel input is needed without which the storage is not realizable at all. Then, the question arises how to handle this extra fuel input when efficiency is to be calculated (see Figure 6(c)). This issue is discussed below.

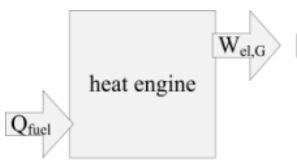

(a)

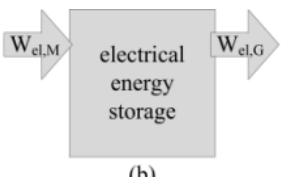

(b)

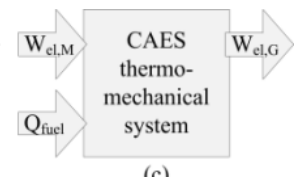

(c)
Figure 6. Input and output streams required for efficiency definition of different types of processes (a) heat engines, (b) electrical energy storage systems and (c) thermomechanical systems such as Compressed Air Energy Storage.

\section{- CAES Efficiency}

In the context of CAES, an efficiency ( $\left.\eta_{\text {caes }}\right)$ defined as

$$
\eta_{\text {caes }}=\frac{\left|W_{e l, G}\right|}{W_{e l, G}+Q_{\text {fuel }}}
$$

is commonly used with the electrical work generated $\left(W_{e l, G}\right)$ and consumed $\left(W_{e l, M}\right)$, respectively, and the fuel enthalpy $\left(Q_{\text {fuel }}\right)$, as depicted in Figure 1 or Figure 6(c).

The relation with the above estimated specific technical work is given by estimating the overall energy taken from the grid through $W_{e l, M}=W_{c} / \eta_{\text {mech }}=\dot{m}_{c} / \eta_{\text {mech }} \cdot \int_{0}^{t c} w_{t, c} d t$ for constant mass flow rate $\left(\dot{m}_{c}\right)$ and with $t_{c}$ being the duration of the charging cycle.

The specific technical work of compression, in the full load pressure range, increases approximately linearly from a minimum value of $504.3 \mathrm{~kJ} / \mathrm{kg}$ at a cavern pressure of 46 bar to a maximum value of $565.3 \mathrm{~kJ} / \mathrm{kg}$ at $68 \mathrm{bar}$ (see Table 2) during one full load charging period $t_{c}=19.8$ hours (assuming an isothermal cavern). Since the air mass flow $\left(\dot{m}_{c}\right)$ is constant at $108 \mathrm{~kg} / \mathrm{s}$ the total compression work $\mathrm{W}_{\mathrm{c}}=$ $\dot{\mathrm{m}}_{\mathrm{c}} \cdot \int_{0}^{t c} w_{t, c}(t) d t$ amounts to $1144 \mathrm{MWh}$. With a mechanical efficiency $\eta_{\text {mech }}=0.9$ (see Table 3 ), the energy taken from the grid amounts to $W_{e l, M}=W_{d} / \eta_{\text {mech }}=1271 \mathrm{MWh}$ (for an isothermal cavern).

The calculation of $W_{e l, G}$ is simpler since the specific technical work is constant $\left(\dot{m}_{d}(t)=\right.$ const. $)$ throughout the full load discharging period $\left(t_{d}\right)$, thus

$$
W_{e l, G}=\eta_{\text {mech }} \cdot \dot{m}_{d} \cdot \int_{0}^{t d} w_{t, T}(t) d t=\eta_{\text {mech }} \cdot \dot{m}_{d} \cdot w_{t, T} \cdot t_{d}=
$$

$1514 \mathrm{MWh}$. Similarly $Q_{\text {fuel }}=\dot{m}_{d} \cdot q_{\text {fuel }} \cdot t_{d}=2520 \mathrm{MWh}$ (for an isothermal cavern). Inserting the above values into Eq.(11) provides the efficiency of $39.9 \%$.

Crotogino [12] estimated the Huntorf plant efficiency (probably using the above definition) to be around $42 \%$ and since then it is widely accepted as a reference value for the plant [26-30].

Under reversibility assumption $\left(\eta_{\mathrm{s}}=1\right)$ the CAES efficiency value of the Huntorf plant would reach $\eta_{\text {caes }}($ reversible $)=47.9 \%$.

Even though $\eta_{\text {caes }}$ as defined in Eq. (11) is very simple and stringent, it is limited to a comparison of fuel-driven processes that are having both, electrical and fuel energy inputs.

\section{- Thermal Efficiency}

By analogy to fuel-driven energy conversion processes (heat engines), a thermal efficiency $\left(\eta_{t h}\right)$ can be defined as [3]:

$\eta_{\mathrm{th}}=\frac{\left|W_{e l, G}\right|-W_{e L, M}}{Q_{\text {fuel }}}$

For the Huntorf CAES process a value of $\eta_{t h}=9.6 \%$ applies. For a reversible representation of the Huntorf plant a value of $\eta_{t h}($ reversible $)=28 \%$ is applicable.

Such defined thermal efficiency $\left(\eta_{\text {th }}\right)$ allows a comparison to other heat engines, like conventional gas turbines, and shows that the thermal efficiency of a CAES process like Huntorf is inferior to the thermal efficiency of a comparable gas turbine. Nevertheless, one has to point out that the electrical energy used for the compression may originate from renewable energy sources and then the net value of turbine work minus compression work (used as numerator in Eq.(12)) is somewhat misleading. Obviously, Eq. (12) in only applicable when $\mathrm{Q}_{\text {fuel }}>0$ and is therefore not usable for ACAES or other pure electrical energy storage systems at all.

\section{- Heat Rate}

The heat rate defined as

$h r_{1}=\frac{1}{\eta_{t h}}=\frac{\left|W_{e l, G}\right|-W_{e L, M}}{Q_{\text {fuel }}}$

$h r_{2}=\frac{\left|W_{e l, G}\right|}{Q_{\text {fuel }}} \quad\left(W_{e l, M}\right.$ omitted $)$

can be applied to heat engines, CAES, and pure electrical energy storage technologies with little constraints. The heat rate is the amount of fuel energy used per electrical energy supplied to the grid and often expressed in $\left[\mathrm{kWh}_{\text {fuel }} / \mathrm{kWh}_{\text {electric }}\right]$. Conventional gas turbines have characteristic values of $h r_{1}=2.7 \mathrm{kWh}$ fuel $/ \mathrm{kWh}_{\text {electric }}$ (e.g. Siemens SGT-800). For CAES the compression work, that is ideally driven by a surplus of renewable power is omitted, hence, the heat rate is $h r_{2}=Q_{f u e} / W_{e l, G}=1.7$ $\mathrm{kWh}_{\text {fuel }} / \mathrm{kWh}_{\text {electric, }}$ which is considerably lower than values applicable to gas turbines (this fact was highlighted in the early CAES-studies as an asset of CAES [31]). Obviously, for an electrical energy storage facility operating without fuel firing $h r=0$ (see Table 4) 
Table 4. Heat Rate (hr) for several energy storage technologies in comparison with Siemens SGT-800 turbine.

\begin{tabular}{ll}
\hline Technology & $\begin{array}{l}\text { heat rate } \\
\text { in }[\mathrm{kWh} \text { fuel } / \mathrm{kWh} \text { electric }]\end{array}$ \\
\hline Gas turbine Siemens SGT-800 & 2.7 \\
CAES Huntorf & 1.7 \\
ACAES & 0 \\
Pumped Hydro Energy Storage & 0 \\
Battery & 0 \\
\hline
\end{tabular}

\section{- Round Trip Efficiencies}

When considering CAES as a means for storing electrical energy, the round trip efficiency $\left(\eta_{r t}\right)$ of electrical energy storage facilities, defined as a ratio of electrical energy supplied to the grid during discharging to energy taken from the grid during charging [32, 33], may be introduced:

$\eta_{\mathrm{rt}}=\frac{\text { electrical energy supplied to the grid }}{\text { electrical energy taken from the grid }}$

However, this semantically simple approach does not have much physical sense, since the ratio of $W_{e l, G}$ to $W_{e l, M}$, that is used to calculate $\eta_{\mathrm{rt}}$ of pumped hydro energy storage or batteries would, when applied to CAES, ignore the contribution of the fuel energy and, thus, lead to values $>1$

$\eta_{\mathrm{rt} 1}=\frac{\left|W_{e l, G}\right|}{W_{e L, M}}(>1$ for fuel driven CAES $)$

Using the above presented data for Huntorf CAES, a value of $\eta_{r t l}=119 \%$ is obtained. Thus, another calculation method has to be developed that distinguishes the contributions of the fuel and the electrical energies. This can be achieved in two ways: (a) by converting the fuel enthalpy into an electrical energy equivalent using a reference efficiency $\left(\eta_{\text {ref }}\right)$ or (b) by calculating the fraction of the energy taken from the grid during charging that is returned to the grid during discharging.

For the first option (a), the following two definitions have been used frequently in literature [29, 33-36]:

$$
\eta_{r t 2}=\frac{\left|W_{e L, G}\right|}{W_{e L, M}+Q_{\text {fuel }} \eta_{r e f}}
$$

or $[9,33,37]$ :

$\eta_{r t 2}=\frac{\left|W_{e L, G}\right|-Q_{\text {fuel }} \eta_{r e f}}{W_{e L, M}}$

The reference efficiency is taken arbitrarily; values of 0.4 [34, 36, 37], 0.476 [33], 0.5 [35] or 0.6 [37] can be found (see also [9]). With $\eta_{\text {ref }}=0.4$, the round trip efficiencies of Huntorf are $\eta_{r t 2}=64.4 \%$ and $\eta_{r t 3}=39.8 \%$.

In the second option (b), the electrical energy taken from the grid $\left(\mathrm{W}_{\mathrm{el}, \mathrm{M}}\right)$ is reduced by the mechanical efficiency of the compressor and the heat losses during inter- and after-cooling, which gives the actual energy content of the stored air as $E_{a i r}=W_{e l, M} \cdot \eta_{\text {mech }}-Q_{\text {loss. }}$ During discharging this energy is further reduced by the conversion efficiency of the turbine $\left(\eta_{t c}=\mathrm{W}_{\mathrm{el}, \mathrm{G}} /\left(\mathrm{E}_{\mathrm{air}}+\mathrm{Q}_{\text {fuel }}\right)\right)$. The resulting value is set into relation with the amount of energy that was originally taken from the grid $\left(\mathrm{W}_{\mathrm{el}, \mathrm{M}}\right)$, hence $\eta_{t, 4}=E_{a i r} \cdot \eta_{t c} / W_{e l, M}$ which is equal to Eq.(17).

$$
\eta_{r t 4}=\frac{\left.W_{e L, M} \eta_{\mathrm{mech}}-Q_{\mathrm{loss}}\right)\left(W_{e L, G} /\left(W_{e L, M} \eta_{\mathrm{mech}}-Q_{\mathrm{loss}}+Q_{f u e l}\right)\right)}{W_{e L, M}}
$$

In other words, $\eta_{r t 4}$ shows what fraction of the electrical energy taken from the grid is then returned to the grid after being stored as compressed air.

Since the heat dissipated during inter cooling $\left(\mathrm{q}_{\text {loss }}\right)$ is $473 \mathrm{~kJ} / \mathrm{kg}$ (for $46 \mathrm{bar}$ cavern pressure) and $538 \mathrm{~kJ} / \mathrm{kg}$ (for 68 bar cavern pressure) (see Table 2) we can estimate the overall heat loss $\left(Q_{\text {loss }}=\dot{m} \int_{0}^{t c} q_{\text {loss }}(t) d t \cdot\right)$ to be $Q_{\text {loss }}=1081$ MWh for charging the caverns from 46 bar to 68 bar pressure over the $19.6 \mathrm{~h}$ period.

The energy content of the compressed and stored air is then $E_{\text {air }}=W_{c}-Q_{\text {loss }}=(1144-1081) \mathrm{MWh}=63 \mathrm{MWh}$.

On discharging, this compressed air energy (63 MWh) as well as the fuel energy (2520 MWh) enter the turbines and generate $322 \mathrm{MW}$ power during 4.7 hours, which is an energy of $1513 \mathrm{MWh}$. Thus, the turbine conversion coefficient $\left(\eta_{t c}\right)$ is 0.586 . This turbine efficiency is considerably higher than for typical gas turbines. Hence, the $63 \mathrm{MWh}$ energy stored in the compressed air is then converted in the turbines into $63 \mathrm{MWh} \cdot 0.586=37 \mathrm{MWh}$ work delivered back to the electrical grid. Figure 7 shows the Sankey diagram based on the above values.

Finally, the electrical energy storage round trip efficiency $\left(\eta_{r t 4}\right)$, as defined by Eq. (17), is $\eta_{r t 4}=37$ $\mathrm{MWh} / 1,271 \mathrm{MWh}=2.9 \%$ which is a very low figure. Eq.(17) can also be written as $\eta_{r t 4}=\eta_{c c} \cdot \eta_{t c}$, where $\eta_{c c}$ stands for the compressor conversion factor (in equivalence to $\eta_{t c}$ for the turbines) and amounts to $\eta_{c c}=E_{\text {air }} / W_{\text {grid }}=0.049$. It is then apparent that as long as the heat removed during compression is wasted and not being recovered in the expansion, the electrical energy storage efficiency will remain very low, indeed.

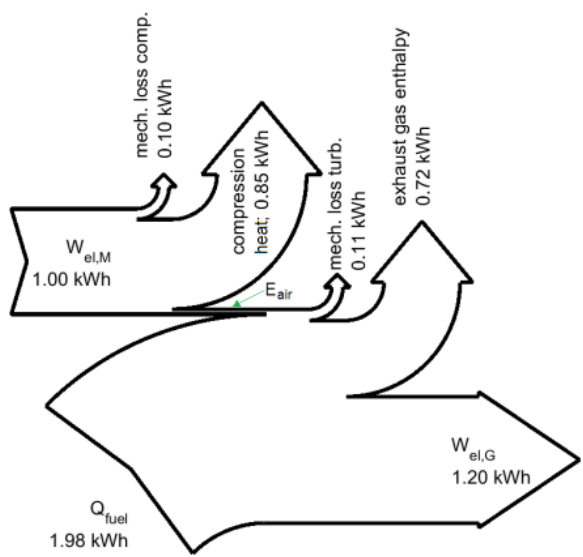

Figure 7: Sankey diagram of Huntorf CAES (figures in MWh for an isothermal cavern)

Table 5. Comparison of the different efficiencies and heat rates for the Huntorf CAES.

\begin{tabular}{lllllllll} 
& $\eta_{\text {caes }}$ & $\eta_{\text {th }}$ & $\eta_{\text {rt1 }}$ & $\eta_{\text {rt2 }}$ & $\eta_{\text {rt3 }}$ & $\eta_{\text {rt4 }}$ & $\mathbf{h r}_{1}$ & $\mathbf{h r}_{2}$ \\
& $\%$ & $\%$ & $\%$ & $\%$ & $\%$ & $\%$ & $\mathrm{kWh} / \mathrm{kWh}$ \\
Huntorf & 39.9 & 9.6 & 119.1 & 66.4 & 39.9 & 2.9 & 10.4 & 1.7 \\
\hline
\end{tabular}

In summary of this section, it can be stated that there is no universal electrical energy storage efficiency for CAES 
which is driven by both, electrical and thermal energies. If one disregards the $119.1 \%$ figure $\left(\eta_{r t 1}\right.$, see Table 5$)$, the Huntorf CAES efficiencies span the range from $2.9 \%$ to $66.4 \%$ depending on the efficiency definition applied. The drawbacks of these definitions are summarized in Table 6 . Hence, the most revealing definition has to be chosen for specific applications; when several thermo-mechanical concepts are compared $\eta_{\text {caes }}$ can be used; when it comes to heat engines $\eta_{\text {th }}$ and $h r$ are useful. Today's main focus is on energy storage applications, and thus, when it comes to comparing electrical energy storage devices, such as batteries or pumped hydro energy storage plants, any of the round trip efficiencies $\eta_{r t 1}$ to $\eta_{r t 4}$ are useful but must be properly defined and should be supplemented by the $h r$ to highlight the fact that fuel is needed to run the CAES process. For ACAES the above efficiency discussion is redundant, because no fuel is added to the process, hence $\eta_{r t l}$ is applicable.

Table 6. Drawbacks of the different efficiency values

\begin{tabular}{lll}
\hline Symbol & Eq. & Drawback \\
\hline$\eta_{\text {caes }}$ & $(11)$ & limited to thermo-mechanical concepts \\
$\eta_{t h}$ & $(12)$ & limited to heat engines \\
$h r$ & $(13)$ & applicable when fuel energy is used \\
$\eta_{r t 1}$ & $(14)$ & limited to pure electrical energy storage \\
$\eta_{r t 2}$ & $(15)$ & includes the arbitrary factor $\eta_{r e f}$ \\
$\eta_{r t 3}$ & $(16)$ & includes the arbitrary factor $\eta_{r e f}$ \\
$\eta_{r t 4}$ & $(17)$ & enthalpy-based \\
\hline
\end{tabular}

\section{CAES Concepts in Comparison}

An in-depth analysis of several other CAES concepts in analogy to the above presented Huntorf analysis has been carried out. Calculation details can be found in the working paper [8]. In the following the values and results obtained in these calculations are used.

\subsection{Huntorf \& McIntosh}

When comparing the two existing CAES plants, Huntorf and McIntosh, it is found that their processes are quite similar. The plant layouts, process temperatures and pressures are comparable. Both plants rely on throttling to enable a constant turbine inlet pressure. The cavern pressures are also comparable with a maximum value of 68 bar (Huntorf) and 75 bar (McIntosh) and a minimum value of 46 bar (Huntorf) and 50 bar (McIntosh). In both cases the compression conversion factor $\eta_{c c}$ is around $5 \%$. Yet, the overall efficiency values of McIntosh are considerably higher than Huntorf's (see Table 7) which is due to the exhaust enthalpy recuperation as well as higher inner and mechanical efficiencies. If the exhaust enthalpy recuperation of the McIntosh plant were not taken into account lower efficiencies would result. Such a calculation has been carried out and the results are presented in Table 7 as McIntosh*.

Table 7. Comparison of different efficiency values; McIntosh* - the McIntosh process without exhaust enthalpy recuperator; ISACOAST* - ISACOAST process with a lower maximum temperatures (n.a. = not applicable).

\begin{tabular}{|c|c|c|c|c|c|c|c|c|}
\hline & $\begin{array}{l}\eta_{\text {caes }} \\
\%\end{array}$ & $\begin{array}{l}\eta_{t h} \\
\%\end{array}$ & $\begin{array}{l}\eta_{r t 1} \\
\% \\
\end{array}$ & $\begin{array}{l}\eta_{r t 2} \\
\% \\
\end{array}$ & $\begin{array}{l}\eta_{r t 3} \\
\% \\
\end{array}$ & $\begin{array}{l}\eta_{r t 4} \\
\% \\
\end{array}$ & $\begin{array}{l}\boldsymbol{h} \boldsymbol{r}_{\boldsymbol{I}} \\
\mathrm{kWh} / \mathrm{k}\end{array}$ & $\begin{array}{r}\boldsymbol{h} \boldsymbol{r}_{2} \\
\mathrm{Wh} \\
\end{array}$ \\
\hline Huntorf & 39.9 & 9.6 & 119.1 & 66.4 & 39.9 & 2.9 & 10.4 & 1.7 \\
\hline McIntosh & 52.3 & 22.6 & 136.1 & 83.0 & 72.1 & 4.5 & 4.4 & 1.2 \\
\hline McIntosh* & 44.2 & 17.4 & 136.1 & 74.4 & 53.1 & 3.5 & 5.7 & 1.5 \\
\hline ADELE & 54.4 & n.a & 54.4 & 54.4 & 54.4 & 54.4 & 0 & 0 \\
\hline ISACOAST & 50.3 & 22.3 & 139.7 & 81.7 & 68.6 & 3.4 & 4.5 & 1.3 \\
\hline ISACOAST* & 53.9 & n.a. & 95.1 & 72.8 & 64.5 & 5.2 & n.a. & 0.8 \\
\hline Sager Meer & 56.9 & n.a. & 56.9 & 56.9 & 56.9 & 56.9 & 0 & 0 \\
\hline
\end{tabular}

\subsection{Advanced Concepts}

Among the advanced concepts considered, the round trip efficiencies of the isobaric CAES concept "ISACOAST" [29] are the highest. These calculated efficiencies can even be increased when taking into account the use of exhaust gas enthalpy in a steam turbine cycle that has not been considered in the calculations above. Nevertheless, this concept is far from realization since temperatures and pressures exceed today's capabilities of gas turbines.

It is then meaningful to recalculate ISACOAST process with a lower maximum temperature limited to $1218 \mathrm{~K}$ which corresponds to Huntorf's $T_{15}$ burner temperature. The so calculated efficiencies are presented in Table 7 as ISACOAST*. It can be observed that the amount of fuel added to the ISACOAST* process is more than halved and the energy output $W_{e l, G}$ is reduced by one third if compared to ISACOAST. Thus, it turns out that ISACOAST* is a net electric energy consumer $\left(\eta_{r t 1}<1\right)$ hence the definition of thermal efficiency $\left(\eta_{\mathrm{th}}\right)$ and heat rate $1\left(h r_{l}\right)$ are not applicable as they result in negative numbers.

The calculated cogeneration efficiency of the quasiisothermal CAES concept "Sager Meer" is very high, yet since in none of the other concepts a cogeneration has been taken into account, the upper value of $88 \%$ may be misleading. The round trip efficiency of $56.9 \%$ is a representative figure that is close to the adiabatic CAES “ADELE" efficiency of $54.4 \%$.

\section{Discussion}

In preceding sections, we have carried out the thermodynamic analysis of the Huntorf plants. In conjunction with the working paper [8] in which also the McIntosh CAES plant as well as several advanced CAES concepts are considered in detail, treating the air as a real gas and taking into account irreversibilities of both the compression and the expansion. As pointed out in the introduction, numerous publications which focus on new CAES concepts use thermodynamics of reversible processes and/or ideal gas (Clapeyron) EOS [36, 38-40]. The availability of Huntorf plant operational data listed in Table A1 puts us in a unique position to be able (a) to estimate the inner and mechanical efficiencies (see Table 1 and Table 3, respectively) and (b) to assess the effect of various thermodynamic assumptions on the calculated efficiencies. The latter is shown in Table 8 by the calculated Huntorf plant efficiencies using reversible/irreversible thermodynamics and ideal gas/real gas EOS.

Table 8. Comparison of the efficiency values of Huntorf (as calculated above, using irreversible thermodynamics and the EOS for real gases in comparison with values obtained for reversible process and/or ideal gas (Clapeyron) EOS.

\begin{tabular}{|c|c|c|c|c|c|c|c|c|}
\hline & $\begin{array}{l}\eta_{\text {caes }} \\
\%\end{array}$ & $\begin{array}{l}\eta_{\text {th }} \\
\%\end{array}$ & $\begin{array}{l}\eta_{\mathrm{rt1}} \\
\%\end{array}$ & $\begin{array}{l}\eta_{\mathrm{rt} 2} \\
\% \\
\end{array}$ & $\begin{array}{l}\eta_{\mathrm{rt3} 3} \\
\% \\
\end{array}$ & $\begin{array}{l}\eta_{\mathrm{rt} 4} \\
\% \\
\end{array}$ & $\begin{array}{l}\mathrm{hr}_{1} \\
\mathrm{kWh} / \mathrm{k}\end{array}$ & $\begin{array}{r}\mathrm{hr}_{2} \\
\mathrm{kWh} \\
\end{array}$ \\
\hline $\begin{array}{l}\text { Huntorf } \\
\text { real gas, } \\
\text { irrev. }\end{array}$ & 39.9 & 9.6 & 119.1 & 66.4 & 39.9 & 2.9 & 10.4 & 1.7 \\
\hline real gas, rev. & 47.8 & 28 & 173.8 & 84.7 & 68.5 & 4.1 & 3.6 & 1.5 \\
\hline id. gas, irrev. & 42.6 & 13.5 & 126.6 & 70.8 & 47.8 & 4.1 & 7.4 & 1.6 \\
\hline id. gas, rev. & 50.8 & 32 & 184 & 89.8 & 79.1 & 5.8 & 3.1 & 1.4 \\
\hline
\end{tabular}

\subsection{Irreversible vs. Reversible Thermodynamics}

The assumption of reversibility $\left(\eta_{s}=1\right)$ clearly leads to an overestimation of the overall efficiency. When the air is treated as a real gas and reversible thermodynamics is used, the CAES efficiency $\eta_{\text {caes }}$ is overestimated by around 8 
percent points (47.8\% against $39.9 \%$, see Table 8 ) which corresponds to a relative error of almost $20 \%$.

The largest error can be observed in the thermal efficiency values. Under reversibility assumptions a thermal efficiency $\eta_{t h}$ (reversible $)=28.0 \%$ is found which is 18.4 percent points higher than the value that results from calculations with irreversible thermodynamics, hence a relative error of $191.6 \%$ applies. Again, we ignore here the round trip efficiency $\eta_{r t l}$ since it is not applicable to Huntorf process as it has been pointed out previously.

The round trip efficiencies $\eta_{\mathrm{r} 2 / 3 / 4}$ are $18.3,28.7$ and 1.2 percent points too high corresponding to relative errors of 27.6, 72.1 and $63.3 \%$, respectively. The heat rates calculated with reversibility assumption are also too optimistic. For air as real gas $h r_{l}$ shows a relative error of $65 \%$ (3.6 against 10.4). The relative error of the $\mathrm{hr}_{2}$ is lower with $12 \%$ (1.5 against 1.7$)$.

These absolute and relative errors are in the same order of magnitude when comparing the results of irreversible and reversible thermodynamics using the ideal gas law.

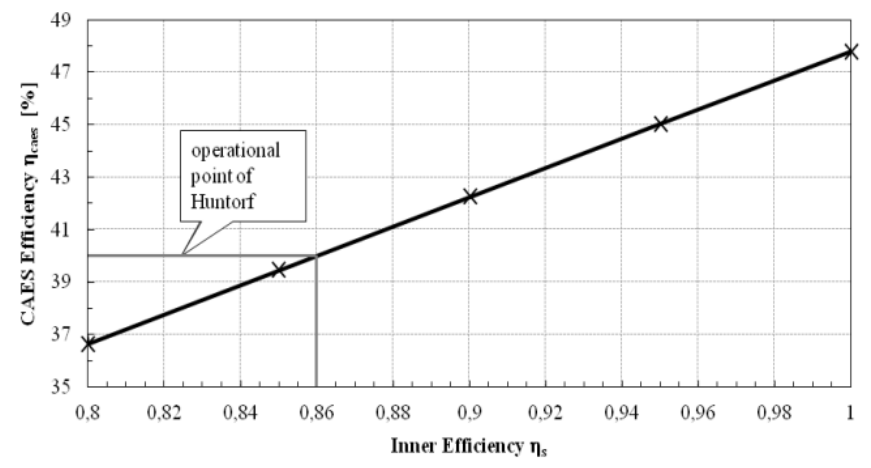

Figure 8. Effect of the inner efficiency $\left(\eta_{s}\right)$ on the CAES efficiency $\left(\eta_{\text {caes }}\right)$ for Huntorf.

Thus, the inner efficiency $\eta_{s}$ has a major impact on the resulting efficiencies, as illustrated in Figure 8 (in producing Figure 8 , the inner efficiencies $\left(\eta_{s}\right)$ of compression and expansion have been taken as equal). The figure also shows that the inner efficiency of the turbines has a larger impact on the overall efficiency than the inner efficiency of the compressors, since for a CAES efficiency ( $\left.\eta_{\text {caes }}\right)$ of approximately $40 \%$ (which corresponds to the Huntorf plant) an inner efficiency of 0.860 is found, as marked in Figure 8. This value is closer to the value of the actual inner efficiency of the turbines (0.894) than of the compressors (mean value of 0.747 , see Table 1 ). This is to be expected since the contribution of the compression part to the overall energy output is rather small, as illustrated by the energy flow diagram (Figure 7).

\subsection{Real vs. Ideal Gas}

As shown in Table 8 the CAES efficiency $\eta_{\text {caes }}$ is over estimated by $2.7 \%$ (42.6\% against $39.9 \%$ ) when ideal gas law is used. Again, the thermal efficiency $\eta_{\text {th }}$ shows the largest deviation with an absolute difference of 4.9 percent points $(13.5 \%$ against $9.6 \%$ ) corresponding to the relative error of $51 \%$. The round trip efficiencies $\eta_{\mathrm{r} t 2 / 3 / 4}$ are also over estimated when the ideal gas assumption is applied.

A closer examination of the process variables reveals that calculations based on ideal gas EOS show a lack of precision in the storage state where low temperatures and high pressures prevail and, thus, the ideal gas EOS is inaccurate. Hence, the efficiency values $\eta_{\text {caes }}$ and $\eta_{r t 2}$ calculated based on figures from ideal gas EOS are over estimated by approximately $7 \%$ compared to those values calculated with real gas assumptions. The relative errors of the heat rates are $29 \%$ for $h r_{1}$ or $6 \%$ for $h r_{2}$, respectively.

\subsection{Irreversible Thermodynamics and Real Gas EOS versus Reversible thermodynamics and Ideal Gas EOS}

When both simplifying assumptions, namely the ideal gas law and the reversible thermodynamics, are used the calculated efficiencies deviate substantially from the plant values. The Huntorf CAES efficiency is then overestimated by 10.9 percent points $(50.8 \%$ against $39.9 \%)$ giving a relative error of $27.3 \%$; the round trip efficiencies $\eta_{r t 2 / 3 / 4}$ are $23.4,39.2$ and 2.9 percent point too large which corresponds to relative errors of $35.2,98.7$ and $100 \%$, respectively. The relative errors of the heat rates amount to $70 \%$ for $\mathrm{hr}_{1}$ or $18 \%$ for $\mathrm{hr}_{2}$.

\subsection{Ambient Air Conditions}

In our calculations, a constant ambient air temperature of $283 \mathrm{~K}$ is used. Yet, the efficiencies vary with ambient air temperature. For example, on a warm summer day of 313 $\mathrm{K}$, the thermal efficiency $\left(\eta_{\mathrm{th}}\right)$ of Huntorf CAES is two percent points lower. For a winter day of $263 \mathrm{~K}$ ambient temperature, the efficiency values rise between 1 and 1.5 percent points. This effect would even be higher if the intercooling temperature of the compression were coupled to the ambient temperature, which is not the case in the calculations at hand, since a constant cooling water temperature of $283 \mathrm{~K}$ is assumed.

The ambient pressure is set to 1.01325 bar. Changes in the 0.925 to 1.070 bar range that correspond to extreme weather situations, lead to negligible variations (+/- 0.5 percent points) of the process parameters and efficiency.

\subsection{Salt Cavern Thermodynamics}

Thermodynamic effects of compression and expansion during storage inside a salt cavern have not been taken into account. During charging of the cavern, the temperature of the stored air rises and with a rising temperature heat losses to the surrounding salt rocks increase [41,42]. During discharging opposite effects occur. To account these effects time dependent simulations [20-25] are required.

\subsection{Carnot's Theorem}

The efficiency defined by Sadi Carnot as upper limit for any heat engine is calculated as $\eta_{\text {Carnot }}=1-T_{\text {cold }} / T_{\text {hot }}$. For the McIntosh CAES process we obtain $\eta_{\text {Carnot }}(\mathrm{McIntosh})=$ $1-283 \mathrm{~K} / 1144 \mathrm{~K}=0.75$. Yet, we found that the combustion turbine process of McIntosh has a large fuel conversion efficiency $\eta_{t c}=0.80$. Thus, by separating the compression from the rest of the combustion and expansion process (e.g. by driving the compression entirely with renewable electricity) the remaining heat engine process can operate beyond Carnot's limits as CAES turbines are not part of a thermodynamic cycle, but the cycle is split into several processes.

\section{Results}

This review presents a detailed thermodynamic analysis of the reference CAES plant Huntorf and a comparison with McIntosh CAES plant and advanced adiabatic, isobaric and 
quasi-isothermal CAES concepts under development. The processes are considered at steady-state and as irreversible with air being treated as a real gas. A new comprehensive set of Huntorf plant thermodynamic data has been collected. The data allows for accurate estimate of thermodynamic inner efficiencies of individual compression/ expansion stages. The calculation for the Huntorf plant serves to develop and validate the calculation methods and are used to test several thermodynamic assumptions concerning both irreversibility and Equation of State (EOS). These methods are then applied to the advanced CAES systems to evaluate all concepts by using a consistent evaluation methodology.

\subsection{Thermodynamic Assumptions}

- Realistic Inner Efficiencies.

Usage of irreversible thermodynamics is crucial for an accurate representation of the CAES processes. The assumption of reversibility leads to an underestimate of process temperatures and entails an underestimate of technical work for compression and overestimate of technical work for expansion, resulting in a considerable overestimate of efficiency values. Depending on the actual efficiency definition, relative errors in excess of $100 \%$ can occur if reversible thermodynamics is used.

Hence, the inner efficiency $\left(\eta_{s}\right)$ has to be taken into account and - due to its strong impact - should be chosen carefully. We estimate that for low-pressure compressors (up to 10 bar) an inner efficiency of $\eta_{\mathrm{s}}=0.90$ or 0.91 can be used. For higher pressures figures of 0.80 to 0.85 are appropriate. Turbine inner efficiencies should be in the 0.88 to 0.91 range for a realistic process design. In our opinion, the use of inner efficiencies larger than 0.91 in CAES calculations that represent the state of the art is unjustifiable.

- Air as Real Gas.

For thermodynamic considerations of a CAES, we advocate the usage of an equation of state (EOS) that treats the (compressed) air as real gas. Even though the calculation with Clapeyron EOS delivers a good approximation of the process state points during compression and expansion, the storage is poorly represented and the resulting efficiency values tend to be too high. When Clapeyron EOS has been used, in the Huntorf case, the CAES efficiency $\eta_{\text {caes }}$ and round trip efficiency $\eta_{\mathrm{rt} 2}$ are overestimated by 2.7 (42.6\% against $39.9 \%)$ and $4.4(70.8 \%$ against $66.4 \%)$ percent points, respectively, which corresponds in both cases to $7 \%$ relative error.

\subsection{Performance Criteria}

To characterize energy storage facilities the round trip efficiency is a helpful information. For an adiabatic CAES, where no fuel is added to the process, the efficiency is simply defined as ratio of output to input electrical energy. Such efficiency is simple and unambiguous. Yet, in fueldriven CAES concepts, due to the input of both, fuel and electrical energy, there is no unambiguous round trip electrical energy storage efficiency. Thus, an efficiency of fuel-driven CAES is not a self-explanatory figure, but has to be supplemented by the calculation method. Different commonly used efficiency definitions have been examined and their drawbacks have been identified (see Table 6).

\subsubsection{Fuel-driven CAES}

We have introduced a 'pragmatic' round trip efficiency $\eta_{r t 4}$ which is the ratio of the electrical energy returned to the grid during repowering to the energy taken from the grid during charging. For Huntorf CAES plant this efficiency is around 3\% while for McIntosh a figure of $4 \%$ is applicable. The reason for such low figures is the thermodynamic inefficiency of compression during which $95 \%$ of the electrical energy taken from the grid is dissipated into heat. Hence, only $5 \%$ is stored in the compressed air which is then converted in the turbine train into electricity. The turbine conversion coefficient $\left(\eta_{t c}\right)$ of Huntorf amounts to 0.59 , thus $\eta_{r t 4}$ round trip efficiency, as defined in Eq. (17), is $3 \%$.

For McIntosh CAES plant the efficiency is a bit larger $\left(\eta_{r t 4}=4 \%\right)$ since the turbine conversion coefficient $\left(\eta_{t c}\right)$ is as high as 0.80 , due to the exhaust gas enthalpy recovery as well as a large mechanical efficiency of 0.97 .

\subsubsection{Adiabatic CAES}

It is then obvious that storage of compression heat and its recuperation is necessary to increase the overall energy storage efficiency. Hence, further research in adiabatic CAES (ACAES) is advocated. Yet, our calculations show that efficiency values for an ACAES system, such as the $54 \%$ figure for the ADELE project, are far from the often cited $70 \%$ goals and even further from the $80 \%$ figure applicable to Pumped Hydro Energy Storage. Even if one assumes a perfect heat storage with a complete heat recovery the ACAES round trip efficiencies are around $66 \%$.

\subsubsection{Isothermal CAES}

Another option to overcome the waste of heat during compression is the development of near isothermal compression systems. In this paper we examined a quasiisothermal CAES concept that limits the maximum temperatures during compression by a large number of compression stages. Thus, the heat removed during intercooling is stored in analogy to adiabatic plant schemes. The resulting $57 \%$ efficiency is in the same order of magnitude as those calculated for the ACAES plant examined.

As a matter of fact isothermal compressions have been under development [43-44] and for a prototype 1.5 MW system an efficiency of $57 \%$ has been quoted [43] which is in line with our estimates.

\subsubsection{Isobaric CAES}

We have also examined an isobaric CAES concept that avoids throttling of compressed air by using an isobaric air storage reservoir. For the Huntorf plant the effects of such a storage type would be a rise of CAES efficiency by 0.8 percent points ( $40.7 \%$ against $39.9 \%$ ).

Thus, it is to question whether such a small efficiency benefit justifies the extra complexity and costs of an isobaric air storage system. Yet, underwater CAES solutions such as developed by Hydrostor, Inc. [45], Pimm, Garvey \& Drew [46], Wang [47] or [48] new opportunities for CAES.

\section{Conclusions}

Fuel driven CAES can hardly be classified as mechanical energy storage. It rather is a thermodynamic power cycle that is split up into two distinct processes: 
compression driven by (renewable) electricity and fueldriven expansion. Such an expansion process allows for fuel efficiencies beyond Carnot's theorem, as shows the McIntosh CAES power plant with a fuel efficiency (defined as $\left.\eta_{t c}=W_{e l, G} /\left(E_{\text {air }}+Q_{\text {fuel }}\right)\right)$ of $80 \%$ compared to its Carnot efficiency of $75 \%$.

Adiabatic and isothermal CAES however are actual storage systems, but rather thermo-mechanical since thermal energy storage plays a key role. While isobaric CAES seems to be least attractive, isothermal and adiabatic CAES systems offer an interesting storage option which can potentially be used as link between electricity and thermal energy sector. For fuel-driven CAES, however, performance parameters have to be handled thoroughly due to their unique features.

\section{List of Acronyms}

\begin{tabular}{ll}
\hline ACAES & Adiabatic Compressed Air Energy Storage \\
ADELE & Adiabatic Compressed Air Energy Storage for \\
& Electricity Supply \\
B & Burner \\
C & Compressor \\
CAES & Compressed Air Energy Storage \\
EOS & Equation of State \\
G & Generator \\
HP & High Pressure \\
ISACOAST & Isobaric Adiabatic Compressed Air Energy \\
& Storage \\
LCV & Lower Calorific Value \\
LP & Low Pressure \\
M & Electricity Engine \\
PHES & Pumped Hydro Energy Storage \\
S & Storage place \\
T & Turbine \\
\hline
\end{tabular}

List of Symbols

\begin{tabular}{|c|c|c|}
\hline Symbol & Name & (SI-)Unit \\
\hline$c_{p}$ & $\begin{array}{l}\text { specific heat capacity at constant } \\
\text { pressure }\end{array}$ & $\mathrm{J} / \mathrm{kg}-\mathrm{K}$ \\
\hline$c_{v}$ & $\begin{array}{l}\text { specific heat capacity at constant } \\
\text { volume }\end{array}$ & $\mathrm{J} / \mathrm{kg}-\mathrm{K}$ \\
\hline$h_{i}$ & specific enthalpy at state point $i$ & $\mathrm{~J} / \mathrm{kg}$ \\
\hline$i$ & state point & - \\
\hline$E$ & energy & $\mathrm{J}$ \\
\hline$m$ & mass & $\mathrm{kg}$ \\
\hline$\dot{m}$ & mass flow rate & $\mathrm{kg} / \mathrm{s}$ \\
\hline$\dot{m}_{c}$ & mass flow rate during charging & $\mathrm{kg} / \mathrm{s}$ \\
\hline$\dot{m}_{d}$ & mass flow rate during discharging & $\mathrm{kg} / \mathrm{s}$ \\
\hline$P$ & power & $\mathrm{W}$ \\
\hline$p_{i}$ & pressure at state point $i$ & $\operatorname{bar}\left(=10^{5} \mathrm{~Pa}\right)$ \\
\hline$q$ & specific heat & $\mathrm{J} / \mathrm{kg}$ \\
\hline$Q$ & heat & $\mathrm{J}$ \\
\hline$\dot{Q}$ & heat flow rate (fuel enthalpy rate) & $\mathrm{W}$ \\
\hline$s$ & specific entropy & $\mathrm{J} / \mathrm{kg}-\mathrm{K}$ \\
\hline$T_{i}$ & temperature at state point $i$ & $\mathrm{~K}$ \\
\hline$t$ & time & $\mathrm{s}$ or $\mathrm{h}$ \\
\hline$t_{c}$ & charging duration & $\mathrm{h}(=3600 \mathrm{~s})$ \\
\hline$t_{d}$ & discharging duration & $\mathrm{h}(=3600 \mathrm{~s})$ \\
\hline$V$ & volume & $\mathrm{m}^{3}$ \\
\hline$v_{i}$ & specific volume at state point $i$ & $\mathrm{~m}^{3} / \mathrm{kg}$ \\
\hline$W$ & work & $\mathrm{J}$ \\
\hline$w_{t}$ & specific technical work & $\mathrm{J} / \mathrm{kg}$ \\
\hline$\eta$ & efficiency & - \\
\hline$\xi$ & compression ratio & - \\
\hline
\end{tabular}

Table A1. Operation parameter of Huntorf CAES plant with design data in boldface font [10] and several sets of measured operation data $(t=1$ to 7$)$ ordered by state point numbers $i=1$ to 16 (compare with Figure 3) (*non-steadystate value with minimal permissible limit of 20 bar at plant operation in a part load; $L C V=$ lower calorific value; n.a. = not available)

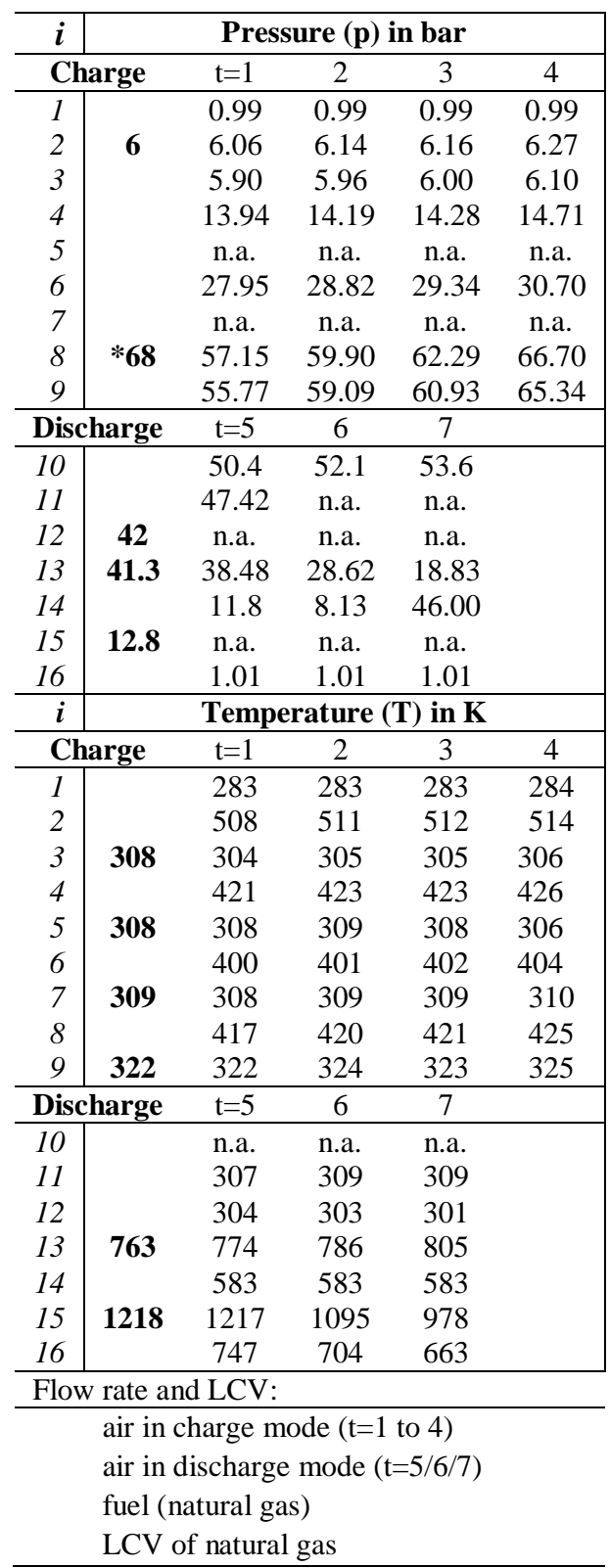

\section{Appendix}


Table A2. Thermodynamic data of Huntorf plant including the design parameter in boldface print (for a cavern pressure of 68 bar).

\begin{tabular}{|c|c|c|c|c|}
\hline$i$ & $\begin{array}{c}(p) \\
\text { in bar } \\
\end{array}$ & Temperature & $\begin{array}{c}\text { Specific } \\
\text { Entropy } \\
(s) \\
\text { in } \mathrm{J} / \mathrm{kg}-\mathrm{K}\end{array}$ & $\begin{array}{c}\text { Specific } \\
\text { Enthalpy } \\
(h) \\
\text { in } \mathrm{J} / \mathrm{kg}\end{array}$ \\
\hline 1 & 1.013 & 283.0 & 6808 & -15.5 \\
\hline 2 & 6.0 & 503.0 & 6879 & 207.6 \\
\hline 3 & 5.99 & 308.0 & 6380 & 8.6 \\
\hline 4 & 13.48 & 418.3 & 6456 & 119.9 \\
\hline 5 & 13.45 & 308.0 & 6143 & 7.1 \\
\hline 6 & 30.27 & 413.1 & 6205 & 113.0 \\
\hline 7 & 30.20 & 309.0 & 5904 & 4.7 \\
\hline 8 & 68.0 & 431.8 & 6009 & 129.6 \\
\hline 9 & 67.20 & 322.0 & 5698 & 11.9 \\
\hline 10 & 67.20 & 322.0 & 5698 & 11.9 \\
\hline 11 & 63.20 & 322.0 & 5718 & 12.6 \\
\hline 12 & 42.00 & 318.6 & 5835 & 12.6 \\
\hline 13 & 41.3 & 763.0 & 6765 & 484.5 \\
\hline 14 & 13.50 & 585.6 & 6804 & 293.5 \\
\hline 15 & 12.8 & 1218.0 & 7634 & 1002.0 \\
\hline 16 & 1.013 & 690.8 & 7738 & 414.9 \\
\hline
\end{tabular}

\section{References}

[1] A. Giramonti, R. D. Lessard, "Exploratory Evaluation of Compressed Air Storage Peak-Power Systems," Energy Sources, 1, 283-294, 1974.

[2] U.S. National Research Council. Assessment of Technology for Advanced Power Cycles: Project Report, Washington, D.C. (1977).

[3] C. Borgnakke, R. C. Sonntag. Fundamentals of thermodynamics. Wiley, Hoboken, N.J, 7th ed., 2009.

[4] C. Lechner, and J. Seume. Stationäre Gasturbinen. Springer, Berlin, Heidelberg, 2010.

[5] H. D. Baehr, S. Kabelac. Thermodynamik: Grundlagen und technische Anwendungen. Springer-Lehrbuch. Springer-Verlag Berlin Heidelberg, Berlin, Heidelberg, 14. aufl edition, 2009.

[6] G. H. Weber, J. F. Weber. Thermodynamik der Energiesysteme: Konventionell - rationell regenerativ. VDE-Verl., Berlin and Offenbach, 2010.

[7] E. W. Lemmon, R. T. Jacobsen, S. G. Penoncello, D. G. Friend, "Thermodynamic Properties of Air and Mixtures of Nitrogen, Argon, and Oxygen From 60 to $2000 \mathrm{~K}$ at Pressures to $2000 \mathrm{MPa}$," J. Phys. Chem. Ref. Data, 29(3), 331-385, 2000.

[8] F. Kaiser, R. Weber, U. Krüger, Thermodynamic Steady-State Analysis and Comparison of Compressed Air Energy Storage (CAES) Concepts. Working paper, 2018

[9] M. Budt, D. Wolf, R. Span, J. Yan, "A review on compressed air energy storage: Basic principles, past milestones and recent developments," Applied Energy, 170, 250-268, 2016.

[10] Brown Boveri \& Cie, "Huntorf Air Storage Gas Turbine Power Plant," Energy Supply, D GK 90202 E:2-14, 1980.

[11] Brown Boveri \& Cie, "Operating Experience with the Huntorf Air Storage Gas Turbine Power Station: D GK 127486 E. Brown Boveri Review, 73, 297-305, 1986.
[12] F. Crotogino, "Druckluftspeicher-GT-Kraftwerke: Ausgleich fluktuierender Stromproduktion," etz elektrotechnik \& automation, 5, 12-18, 2003.

[13] F. Crotogino, K.-U. Mohmeyer, R. Scharf, Huntorf "CAES: More than 20 years of successful operation" Report Spring 2001 Meeting, Orlando.

[14] H. Hoffeins, D. Romeyke, F. Sütterlin, "Die Inbetriebnahme der ersten LuftspeicherGasturbinengruppe: Energieversorgung: Druckschrift Nr. CH GK 113981 D,“ Brown Boveri Mitteilungen, 67, 465-473, 1980.

[15] P. Quast. The Huntorf Plant: Over 3 years operating experience with compressed air caverns. Sonderdruck KBB, Hannover, 1. Edition, 1981.

[16] P. Quast, F. Crotogino, "Initial Experience with the Compressed-Air Energy Storage (CAES) Project of Northwestdeutsche Kraftwerke AG (NWK) at Huntorf/West Germany: Erste Erfahrungen beim Betrieb des Luftspeicherprojektes der Nordwestdeutsche Kraftwerk AG (NWK) in Huntorf," Erdoel-Erdgas-Zeitschrift, 95, 310-314, 1979.

[17] O. Weber, "The Air-Storage Gas Turbine Power Station at Huntorf," Brown Boveri Review, 7/8, 332337, 1975.

[18] VDI. VDI-Wärmeatlas: Mit 320 Tabellen. Springer reference. Springer Vieweg, Berlin, 11., bearb. und erw. aufl edition, 2013.

[19] DVGW Deutsche Vereinigung des Gas- und Wasserfaches e. V. (Mai 2008). Arbeitsblatt G 260: Gasbeschaffenheit, Bonn.

[20] S. K. Khaitan, M. Raju, "Dynamics of hydrogen powered CAES based gas turbine plant using sodium alanate storage system," International Journal of Hydrogen Energy, 37, 18904-18914, 2012.

[21] S. K. Khaitan, M. Raju, "Dynamic simulation of air storage-based gas turbine plants," International Journal of Energy Research, 37, 558-569, 2013.

[22] M. Raju, S. Kumar Khaitan, "Modeling and simulation of compressed air storage in caverns: A case study of the Huntorf plant," Applied Energy, 89, 474-481, 2012.

[23] R. Kushnir, A. Dayan, A. Ullmann, "Temperature and pressure variations within compressed air energy storage caverns," International Journal of Heat and Mass Transfer, 55, 5616-5630, 2012a.

[24] R. Kushnir, A. Ullmann, A. Dayan, “Thermodynamic and hydrodynamic response of compressed air energy storage reservoirs: a review," Reviews in Chemical Engineering, 28,123-148, 2012b.

[25] C. Xia, Y. Zhou, S. Zhou, P. Zhang, F. Wang, "A simplified and unified analytical solution for temperature and pressure variations in compressed air energy storage caverns." Renewable Energy, 74,718-726, 2015.

[26] F. Ausfelder, C. Beilmann, M. Bertau, et al. "Energiespeicherung als Element einer sicheren Energieversorgung," Chemie Ingenieur Technik, 87, 17-89, 2015.

[27] H.-P. Beck, B. Engel, L. Hofmann, R. Menges, T. Turek, and H. Weyer, "Eignung von Speichertechnologien zum Erhalt der 
Systemsicherheit: Abschlussbericht,“ volume 13 of Schriftenreihe des Energie-Forschungszentrums Niedersachsen. Cuvillier Verlag, Göttingen, 2013.

[28] N. Hartmann, L. Eltrop, N. Bauer, J. Salzer, S. Schwarz, and M. Schmidt. Stromspeicherpotenziale für Deutschland: Report by zfes, Universität Stuttgart, 2012.

[29] L. Nielsen, “GuD-Druckluftspeicherkraftwerk mit Wärmespeicher: Promotion an der Technischen Universität Braunschweig,“ volume 14 of Schriftenreihe des Energie-Forschungszentrums Niedersachsen (EFZN). Cuvillier Verlag, Göttingen, 2013.

[30] D. Wolf. "Methods for Design and Application of Adiabatic Compressed Air Energy Storage Based on Dynamic Modeling," vol. 65 of UmsichtSchriftenreihe. Karl Maria Laufen and Laufen, Oberhausen, 1 edition, 2011.

[31] J. B. Bush, J. M. Campbell, P. M. Jarvis, et al. Economic and Technical Feasability Study of Compressed Air Storage: Final Report prepared for U.S. Energy Research and Development Administration, Washington, D.C., 1976.

[32] F. Kaiser, W. Busch, "Der beste Stromspeicher? Pumpspeicher und die Alternativen," In W. Busch, and F. Kaiser, F., editors, Pumpspeicher für die Energiewende - Spitzentechnologie auf Eis?, volume 34 of Schriftenreihe des EnergieForschungszentrums Niedersachsen, pages 72-87, Göttingen. Cuvillier Verlag, 2015.

[33] S. Succar, R. H. Williams. Compressed Air Energy Storage: Theory, Resources and Applications for Wind Power: Report Energy Systems Analysis Group, Princeton University, 2008.

[34] B. Elmegaard, W. Brix, "Efficiency of Compressed Air Energy Storage" In The 24th International Conference on Efficiency, Cost, Optimization, Simulation and Environmental Impact of Energy Systems, 2011

[35] S. D. Garvey, "Two Novel Configurations for Compressed Air Energy Storage Exploiting HighGrade Thermal Energy Storage," presented at UKChina Thermal Energy Storage Forum, Beijing, 2015.

[36] Y.-M. Kim, J.-H. Lee, S.-J. Kim, D. Favrat, "Potential and Evolution of Compressed Air Energy Storage: Energy and Exergy Analyses," Entropy, 14, 1501$1521,2012$.
[37] W.-D. Steinmann, Thermo Mechanical Concepts For Bulk Energy Storage: Manuscript submitted for publication, personal communication, 2016. (unpublished).

[38] G. Grazzini, A. Milazzo, "Thermodynamic analysis of CAES/TES systems for renewable energy plants," Renewable Energy, 33, 1998-2006, 2008.

[39] W. F. Pickard, N. J. Hansing, A. Q. Shen, "Can largescale advanced-adiabatic compressed air energy storage be justified economically in an age of sustainable energy?" Journal of Renewable and Sustainable Energy, 1, 033102, 2009.

[40] N. Hartmann, O. Vöhringer, C. Kruck, L. Eltrop, "Simulation and analysis of different adiabatic Compressed Air Energy Storage plant configurations," Applied Energy, 93, 541-548, 2012.

[41] B. Leuger, and T. Beutel, "Bewertung der Betriebserfahrungen mit der Gasspeicherkaverne Huntorf K6: Felsmechanik/Energiewende, “ mining + geo, 4:674-677, 2012.

[42] P. Schwoeppe, S. Gose, R. Scholz, "Thermodynamische Betrachtungen: Chapter," In Dietz, P., editor, Grundlast von der Nordsee, pages 131-146. Papierflieger, Clausthal-Zellerfeld, 2008.

[43] B. Bollinger. Technology Performance Report SustainX Smart Grid Program: Demonstration of Promising Energy Storage Technologies, Project Report, 2015.

[44] T. McBride, A. Bell, D. Kepshire. ICAES Innovation Foam-Based Heat Exchange: SustainX, Inc. Report, 2013.

[45] C. VanWalleghem. Hydrostor Activates World's First Utility-Scale Underwater Compressed Air Energy Storage System: Press release, 2015.

[46] A. J. Pimm, S. D. Garvey, R. J. Drew, "Shape and cost analysis of pressurized fabric structures for subsea compressed air energy storage." In Proceedings of the Institution of Mechanical Engineers, Part C: Journal of Mechanical Engineering Science, 225, 1027-1043, 2011.

[47] Z. Wang, D. S.-K. Ting, R. Carriveau, W. Xiong, Z. Wang, "Design and thermodynamic analysis of a multi-level underwater compressed air energy storage system," Journal of Energy Storage, 5, 203211, 2016

[48] V. C. Patil, P. I. Ro, "Energy and Exergy Analysis of Ocean Compressed Air Energy Storage Concepts," Journal of Engineering, 2018, 1-14, 2018. 